\title{
Effect of bacterial $\beta$-amylase and fungal $\alpha$-amylase on the digestibility and structural characteristics of potato and arrowroot starches
}

\author{
Flávia Villas-Boas, Célia M.L. Franco* \\ UNESP - São Paulo State University - Department of Food Engineering and Technology, R. Cristóvão Colombo, 2265, CEP 15054-000, São José do Rio Preto,
} São Paulo, Brazil

\section{A R T I C L E I N F O}

\section{Article history:}

Received 21 January 2015

Received in revised form

28 July 2015

Accepted 24 August 2015

Available online 29 August 2015

\section{Keywords:}

Starch

Digestibility

Amylase

Chain length

Structure

\begin{abstract}
A B S T R A C T
Retrograded and debranched starch, known as resistant starch type 3 (RS3), is resistant to digestive enzymes and exhibits a behavior similar to that of dietary fibers. In this study, the effect of $\beta$ - and $\alpha$ amylase on the digestibility and structural characteristics of potato and arrowroot starches was evaluated and compared. Starch samples were gelatinized, hydrolyzed by $\beta$ - or fungal $\alpha$-amylase, debranched, cooled $\left(4^{\circ} \mathrm{C} / 16 \mathrm{~h}\right)$, precipitated with ethanol, and dried. Debranched and gelatinized starch samples were used as control. The degrees of hydrolysis for the two starches were similar $(\sim 25 \%)$, regardless of enzyme used. In both starches, $\beta$-amylase resulted in a significant decreases in average degree of polymerization (DPn) of short chains (from 16.5 to 12) and in proportion of these chains, while fungal $\alpha$-amylase caused a significant decrease in DPn of long chains (from 38.9 to 26.8 and from 35.1 to 28.2 for potato and arrowroot starches, respectively) plus a significant increase in proportion of short chains. Gelatinization enthalpy and relative crystallinity of modified starches increased with amylolysis, particularly when $\alpha$ amylase was used. RS3 content was $20.2 \%$ in the debranched potato starch and increased to $36.5 \%$ with amylolysis, regardless of the enzyme used before debranching. However, slowly digestible starch content increased from $8.5 \%$ to $27.8 \%$ when $\alpha$-amylase was used in this starch. Meanwhile, arrowroot starch had $47.5 \%$ and $53.4 \%$ RS3 contents when $\beta$ - and $\alpha$-amylase were used, respectively. Structural characteristics, particularly the amylopectin branch chain length distribution, are important factors responsible for RS3 formation when amylolysis precedes debranching.
\end{abstract}

() 2015 Elsevier Ltd. All rights reserved.

\section{Introduction}

Starch is the main source of carbohydrates in the human diet. It is composed of two macromolecules: amylose and amylopectin. Amylose is essentially a linear molecule made up of glucose units linked by $\alpha-1-4$ linkage, while amylopectin is highly branched consisting of numerous short chains of (1-4) - $\alpha$-D-glucans that are interconnected by $\alpha-1-6$ linkage. These $\alpha-1-6$ linkages are responsible for ramifications. Starch is hydrolyzed by digestive enzymes into maltose, maltotriose, and branched-limit dextrins, which are then hydrolyzed into glucose to be absorbed into the blood (Kittisuban, Lee, Suphantharika, \& Hamaker, 2014). Starch digestibility varies and, depending on the speed at which it is converted into glucose, starch is classified as (i) rapidly digestible starch (RDS), (ii) slowly digestible starch (SDS), and (iii) resistant

\footnotetext{
* Corresponding author.

E-mail addresses: flavillasb@gmail.com (F. Villas-Boas), celia@ibilce.unesp.br (C.M.L. Franco).
}

starch (RS) (Englyst, Kingman, \& Cummings, 1992).

Slowly digestible starch causes a slow and prolonged release of glucose in the gastrointestinal tract with a low glycemic response. This starch fraction may be useful in the control and prevention of cardiac diseases, type II diabetes, and obesity (Kittisuban et al., 2014).

Resistant starch is defined as the starch or a starch fraction which is not absorbed in the small intestine of healthy individuals (Englyst et al., 1992). By presenting a behavior that is similar to that of dietary fibers, RS has been associated with several health benefits. Numerous studies have shown the positive effects of RS in cases of obesity (Morita et al., 2005), diabetes (Zhou, Meng, Chen, Zhu, \& Yuan, 2014), colon cancer (Liu \& Xu, 2008), and cardiovascular disease (Morita et al., 2005). Depending on its structural characteristics and mechanism through which it is resistant to digestion, RS can be classified into five different types: RS1 represents physically inaccessible starches that are present in grains, RS2 refers to native granular starches such as those found in green bananas and raw potatoes, RS3 represents retrograded starches formed by the reassociation of starch chains, RS4 includes 
chemically modified starches, and RS5 represents those formed by amylose-lipid complexes (Fuentes-Zaragosa et al., 2011; Luckett \& Wang, 2012). Resistant starch type III (RS3) is unique among the types because it is formed by natural processes involving heat and moisture, which in most cases can destroy RS1 and RS2. It has also been found to be highly stable in food processing steps; i.e., it can be used in food production without losing its resistance to enzymatic digestion (Fuentes-Zaragosa et al., 2011). It mainly consists of retrograded amylose because of its strong tendency to reassociate, a feature which thus defines amylose content as the main factor governing RS3 formation (Eerlingen, Deceuninck, \& Delcour, 1993; Luckett \& Wang, 2012). However, Berry (1986) showed that it is possible to enhance starch retrogradation by breaking down amylopectin in linear fragments. Therefore, a common way to increase RS3 content is by debranching enzymes, which, by acting on the starch, release linear fragments with greater mobility for retrogradation. Reddy, Suriya, and Haripriya (2013) evaluated the resistant starch production by debranching bean starch using pullulanase, and they observed that RS content increased from $21.27 \%$ in retrograded starch to $42.34 \%$ after debranching and retrogradation. The amylase action preceding the debranching has been found to be a technique that is able to further increase the RS3 content, since amylase activity breaks down the starch molecules into fragments of low molecular weight and thus interferes in the size of amylose chains and amylopectin side chains. Both chains may affect the retrogradation tendency of the hydrolysis residues. Starch retrogradation rate depends on starch chain length, so the degree of polymerization (DP) of the molecules affects the formation of RS3 (Eerlingen et al., 1993).

A suitable chain length is required for recrystallization (formation of double helices) to form higher RS3 content. However, data on the optimal chain length still are contradictory. Zhou et al. (2014) reported that the decrease in amylose and amylopectin chain lengths increased RS content when bacterial $\alpha$-amylase preceding pullulanase action was used in the formation of RS3 from rice starch. Luckett and Wang (2012) observed that amylose and amylopectin long chains contributed to RS3 formation of maize starches with different amylose contents when $\beta$-amylase was used prior debranching with isoamylase, while Hasjim and Jane (2009) reported that shorter chains obtained by mild acid hydrolysis of corn starch contributed for increasing RS3.

Both $\beta$-amylase and fungal $\alpha$-amylase hydrolyze the $\alpha$-1,4 linkages of starch chains, but their mechanisms of action are different. $\beta$-amylase is an exoenzyme that cleaves the starch chains from the non-reducing end (Luckett \& Wang, 2012), while the action mechanism of $\alpha$-amylase is dependent on enzyme source and substrates (Robyt, 2009). The $\alpha$-amylase from Aspergillus oryzae cleaves $\alpha-1,4$ linkages present in the inner part of the starch chains and has a small but measurable extent of multiple attack in the degradation of malto-oligosaccharides (Allen \& Thoma, 1978).

Most studies have used bacterial $\alpha$ - or $\beta$-amylases before debranching starch to obtain RS3. To the authors' knowledge, this is the first report on using fungal $\alpha$-amylase before debranching for this purpose. This enzyme is cheaper and easier of being obtained than bacterial $\beta$-amylase.

This study aims to evaluate the effects of bacterial $\beta$-amylase and fungal $\alpha$-amylase action followed by debranching with pullulanase on the structural characteristics and digestibility of potato and arrowroot starches.

\section{Material and methods}

\subsection{Material}

Potato (Solanum tuberosum) tubers of the Monalisa cultivar and common variety arrowroot (Maranta arundinacea) were acquired from producers in São Paulo state, Brazil. The $\beta$-amylase from $B a$ cillus cereus (Megazyme International, Ireland), $\alpha$-amylase from $A$. oryzae (Sigma, USA), pullulanase from Bacillus acid pullulyticus (Promozyme 400L, Denmark), pancreatin $\alpha$-amylase (Sigma, USA) and amyloglucosidase from $A$. niger (Sigma, USA) were used in this study.

\subsection{Isolation and chemical composition of starches}

Potato and arrowroot starches were isolated from the tubers and rhizomes, respectively, using wet milling according to the method described by Peroni, Rocha, and Franco (2006). The amounts of proteins, lipids, and ash were determined according to the methods of American Association of Cereal Chemists (AACC., 2000). Phosphorous was determined as described by Smith and Caruso (1964).

The amylopectins of the native starches were isolated as described by Jane and Chen (1992). Iodine affinities of the isolated amylopectins and defatted starches were measured using a potentiometric autotitrator (716 SM Titrino, Metrohm, Switzerland) as described by Kasemsuwan, Jane, Schnable, Stinard, and Robertson (1995). The apparent amylose content was calculated by dividing the iodine affinity of defatted starch by $20 \%$ (Takeda \& Hizukuri, 1987), and absolute amylose content was assessed by subtracting the iodine affinity of isolated amylopectin from that of the defatted starch according to Kasemsuwam et al. (1995). Each analysis was performed in triplicate.

\subsection{Enzymatic treatment}

Potato and arrowroot starches were hydrolyzed with bacterial $\beta$-amylase or fungal $\alpha$-amylase according to the method described by Luckett and Wang (2012) with modifications.

Preliminary tests showed that the percentage of hydrolysis of both of the starches incubated with $400 \mathrm{U} \beta$-amylase/g starch for $6 \mathrm{~h}$ was close to $25 \%$. After this time, the rate of hydrolysis became almost constant. Tests with different concentrations of fungal $\alpha-$ amylase were then carried out over the same $6 \mathrm{~h}$ period of hydrolysis in order to obtain percentages of hydrolysis that were similar to $25 \%$ for both of the starches. The enzymatic treatments were performed as follows: Potato and arrowroot starches (25 g) were suspended in $400 \mathrm{~mL}$ of $0.1 \mathrm{M}$ acetate buffer ( $\mathrm{pH} 6.5$ for hydrolysis with $\beta$-amylase, $\mathrm{pH} 5.0$ for hydrolysis with $\alpha$-amylase), heated in a boiling water bath for $30 \mathrm{~min}$, and autoclaved at $122^{\circ} \mathrm{C}$ for $30 \mathrm{~min}$ to ensure starch gelatinization. The starch solutions were equilibrated in a water bath at $40{ }^{\circ} \mathrm{C}$ in the case of $\beta$-amylase and at $55^{\circ} \mathrm{C}$ in the case of $\alpha$-amylase, and the enzymes were then added (400 U $\beta$-amylase/g of arrowroot or potato starch; $10 \mathrm{U}$ fungal $\alpha$-amylase/g of arrowroot starch; and $5 \mathrm{U}$ fungal $\alpha$-amylase/g of potato starch). The solutions were incubated for $6 \mathrm{~h}$ and then boiled for $30 \mathrm{~min}$ to inactivate the enzymes. The $\beta$ - and $\alpha$-amylase treated starches were precipitated using $2.0 \mathrm{~L}$ of ethanol, and centrifuged at $7000 \mathrm{~g}$ for $20 \mathrm{~min}$. The supernatant was collected and the degree of hydrolysis was determined by measuring the total carbohydrate content using the phenol-sulfuric method, as described by Dubois, Gilles, Hamilton, Rebers, and Smith (1956). The precipitate was kept at $40{ }^{\circ} \mathrm{C}$ for $40 \mathrm{~min}$ to evaporate any residual ethanol and was then lyophilized. Potato and arrowroot gelatinized starches were prepared at the same way as described above, but without using enzymes. In order to certificate that there was no degradation of native starches during autoclaving in different buffers, the potato and arrowroot gelatinized starches were analyzed by GPC using Sepharose CL 2B gel according to Jane and Chen (1992).

The debranching treatment was performed as described by 
Polesi and Sarmento (2011) with modifications. Gelatinized starches (20 g) and $\beta$ - and $\alpha$-amylase treated starches (20 g) were dispersed in $250 \mathrm{~mL}$ of $0.1 \mathrm{M}$ acetate buffer, $\mathrm{pH} 5.3$, and heated in a boiling water bath that was stirred for $50 \mathrm{~min}$. The temperature was equilibrated at $60{ }^{\circ} \mathrm{C}$, and pullulanase was added (40 U/g starch). The samples were incubated at $60^{\circ} \mathrm{C}$ for $10 \mathrm{~h}$ with stirring $(80 \mathrm{rpm})$, followed by inactivation of the enzyme for $20 \mathrm{~min}$ in a boiling water bath.

After the debranching treatment, the starch solutions were kept at room temperature for $20 \mathrm{~min}$ and stored at $4{ }^{\circ} \mathrm{C}$ for $16 \mathrm{~h}$ to enhance the retrogradation process. The samples were precipitated with $1 \mathrm{~L}$ of ethanol, filtered, dried at $40{ }^{\circ} \mathrm{C}$ for $24 \mathrm{~h}$, grounded in a mortar, and kept in desiccators for later use.

\subsection{Distribution of molecular components of starch by gel permeation chromatography (GPC)}

The molecular size distribution of the starch components was determined using a Bio-Gel P6 column according to the procedure described by Song and Jane (2000). Aliquots containing $15 \mathrm{mg}$ of starch were dispersed in $5 \mathrm{~mL}$ of eluent $(25 \mathrm{mM} \mathrm{NaCl}$ and $1 \mathrm{mM}$ $\mathrm{NaOH}$ ), and $1 \mathrm{mg}$ of glucose was added. The mixture was constantly stirred in a boiling water bath for $30 \mathrm{~min}$ and was then cooled to room temperature. A $3.6 \mathrm{~mL}$ aliquot of the mixture that contained $11 \mathrm{mg}$ of starch was applied to the top of a column $(100 \mathrm{~cm}$ height and $1.0 \mathrm{~cm}$ diameter), packed with Bio-Gel P-6, and downwardly eluted at a flow rate of $0.5 \mathrm{~mL} / \mathrm{min}$. Fractions of $2.5 \mathrm{~mL}$ were collected every $5 \mathrm{~min}$ and then analyzed for total carbohydrate through the phenol-sulfuric method (Dubois et al., 1956). The reducing value of each peak was determined by using the ParkJohnson modified method (Hizukuri, Takeda, \& Yasuda, 1981). Chain length determinations were repeated at least two times. The average degree of polymerization was calculated from the ratio of total carbohydrate/reducing value at each peak fractions (peaks II and III) (Jane \& Chen, 1992). The average molecular weight of the fractions II and III was calculated using $\mathrm{Mw}=162 \mathrm{DP}+18$, as described by Avaltroni, Bouquerand, and Normand (2004).

\subsection{Determination of branch chain length distribution of amylopectin}

The amylopectin branch chain length distribution of the modified starches was determined using a HPAEC-PAD system (ICS-5000 Dionex Corporation, USA). The enzyme-treated starch $(50 \mathrm{mg})$ was dispersed in $5 \mathrm{~mL}$ DMSO 90\% solution under boiling and stirring for $1 \mathrm{~h}$, and then under stirring for another $16 \mathrm{~h}$ at room temperature. A solution aliquot $(0.5 \mathrm{~mL})$ was mixed with $2 \mathrm{~mL}$ of absolute ethanol and the precipitated starch was recovered by centrifugation, mixed with $1.8 \mathrm{~mL}$ of ultra-pure water $(18 \mathrm{M} \Omega \mathrm{cm})$ and kept with agitation in the boiling water bath for $30 \mathrm{~min}$. After cooling, $0.2 \mathrm{~mL}$ of acetate buffer $\mathrm{pH}$ 3.5 $0.1 \mathrm{M}$ and $6 \mu \mathrm{L}$ of azide solution $10 \%(\mathrm{w} / \mathrm{v})$ were added. The $\mathrm{pH}$ was adjusted to $6.5-7.0$ with $\mathrm{NaOH} 1 \mathrm{M}$ and the suspension was heated in the boiling water bath for $15 \mathrm{~min}$. After reached the room temperature, the samples were filtered $(0.22 \mu \mathrm{m}$ membrane) and automatically injected into the HPAEC-PAD system $(5 \mathrm{~mL}$ sample loop). The flow rate was $1 \mathrm{~mL} / \mathrm{min}$ at $35^{\circ} \mathrm{C}$. The standard quadruple potential (E) waveform was employed for the following periods and using the following pulse potentials: $\mathrm{E} 1=0.10 \mathrm{~V}$ $\left(\mathrm{t}_{1}=0.40 \mathrm{~s}\right) ; \mathrm{E} 2=-2.00 \mathrm{~V}\left(\mathrm{t}_{2}=0.02 \mathrm{~s}\right) ; \mathrm{E} 3=0.60 \mathrm{~V}\left(\mathrm{t}_{3}=0.01 \mathrm{~s}\right)$; $\mathrm{E} 4=-0.10 \mathrm{~V}\left(\mathrm{t}_{4}=0.06 \mathrm{~s}\right)$. All eluents were prepared using ultrapure water $(18 \mathrm{~m} \Omega \mathrm{cm})$ with $\mathrm{N}_{2}$ sparging. Eluent $A$ was made up of $500 \mathrm{mM} \mathrm{NaOH}$ and eluent B was made up of $150 \mathrm{mM} \mathrm{NaOH}$ and $500 \mathrm{mM}$ sodium acetate. The branched chains of amylopectin were separated using a Dionex CarboPac ${ }^{\mathrm{TM}}$ PA-100 guard column $(4 \mathrm{~mm} \times 50 \mathrm{~mm})$ and a Dionex CarboPac ${ }^{\mathrm{TM}}$ PA-100column
$(4 \mathrm{~mm} \times 250 \mathrm{~mm})$. The gradient of eluent B was $20 \%$ at $0 \mathrm{~min}$, $80 \%$ at $75 \mathrm{~min}$, and $20 \%$ at $80 \mathrm{~min}$. A mixture of maltodextrins (GP 1-7) was used to identify homologous series of long chains. The data were analyzed using the Chromeleon software, version 6.8 (Dionex Corporation). The analyses were performed in duplicate.

\subsection{X-ray diffraction and relative crystallinity}

Native and modified starches were stored for 10 days at $25{ }^{\circ} \mathrm{C}$ and $90 \%$ of relative humidity in a desiccator containing a saturated solution of $\mathrm{BaCl}_{2}$ and $1 \%$ of sodium azide. The X-ray diffraction patterns of the starches were determined using a RINT 2000 Wide Angle Goniometer unit (Rigaku, Japan). Relative crystallinity was quantitatively estimated based on the relationship between the peak and total areas following the method of Nara and Komiya (1983).

\subsection{Thermal properties}

The thermal properties of the starches were determined using a differential scanning calorimeter (DSC - Pyris1, Perkin Elmer, USA). The starch samples ( $3 \mathrm{mg}, \mathrm{db}$ ) were weighed in stainless steel pans, mixed with deionized water $(9 \mu \mathrm{L})$, and sealed. The sealed pans were kept at room temperature for $24 \mathrm{~h}$ to equilibrate and scanned at a rate of $10{ }^{\circ} \mathrm{C} / \mathrm{min}$ over a temperature ranging from $25^{\circ} \mathrm{C}$ to $180^{\circ} \mathrm{C}$. An empty pan was used as a reference. The analysis was performed in triplicate.

\subsection{Digestibility of starches}

Starch digestibility was determined according to the method of Englyst et al. (1992), with modifications. Starch samples (0.5 g) were added to $20 \mathrm{~mL}$ of acetate buffer $(0.1 \mathrm{M}$, pH 5.2) containing $4 \mathrm{mM} \mathrm{CaCl}$ and kept in a water bath at $37^{\circ} \mathrm{C}$. Enzyme solution $(5 \mathrm{~mL})$ containing invertase and pancreatin amyloglucosidase was added. Aliquots of $0.5 \mathrm{~mL}$ were taken at 0,20 , and $120 \mathrm{~min}$. Glucose was measured using a glucose determination kit (Glucose Liquiform - Labtest - Brazil). The values of the different carbohydrate nutritional fractions (rapidly digestible starch, slowly digestible starch, and resistant starch) were obtained by combining the values of G20 (glucose released after 20 min), G120 (glucose released after $120 \mathrm{~min}$ ), FG (free glucose), and TG (total glucose). The samples were analyzed in triplicate.

\subsection{Statistical analysis}

The software Statistica for Windows (v. 5.0, Statsoft, USA) was employed to analyze mean values using analysis of variance (ANOVA) and Person correlation. Differences were evaluated using the t-test with Tukey's adjustment. The significance level was set at a $\mathrm{p}$ value $<0.05$.

\section{Results and discussion}

\subsection{Starch composition}

The starches showed low percentages of lipids, proteins, and ash $(<1 \%)$. The phosphorous is an important non-carbohydrate constituent of starch being present in root and tuber starches mainly as phosphate monoester (Lim, Kasemsuwan, \& Jane, 1994). Phosphorus content was higher in the potato starch, which was found to have $0.097 \%$ of the mineral (Table 1 ). Potato starch naturally has relatively high phosphate content. Phosphorus content can vary depending on the variety of the botanical species, as well as on environmental characteristics and the soil where the plant was 
Table 1

Chemical composition, iodine affinity, and apparent and absolute amylose contents of potato and arrowroot starches.

\begin{tabular}{|c|c|c|c|c|}
\hline Starch & Lipids (\%) & Proteins (\%) & Ash (\%) & Phosphorus (\%) \\
\hline Potato & $0.12(0.0)^{\mathrm{a}}$ & $0.12(0.0)^{\mathrm{a}}$ & $0.26(0.0)^{\mathrm{a}}$ & $0.097(0.0)^{\mathrm{a}}$ \\
\hline \multirow[t]{3}{*}{ Arrowroot } & $0.13(0.0)^{\mathrm{a}}$ & $0.10(0.0)^{\mathrm{a}}$ & $0.17(0.0)^{\mathrm{b}}$ & $0.034(0.0)^{\mathrm{b}}$ \\
\hline & \multicolumn{2}{|c|}{ Iodine Affinity ${ }^{\mathrm{a}}$} & \multicolumn{2}{|c|}{ Amylose content (\%) } \\
\hline & Starch & Amylopectin & Apparent $^{\mathrm{b}}$ & Absolute $^{c}$ \\
\hline Potato & $5.96(0.1)^{\mathrm{a}}$ & $2.3(0.1)^{a}$ & 29.8 & 20.7 \\
\hline Arrowroot & $5.02(0.0)^{b}$ & $1.4(0.0)^{\mathrm{b}}$ & 25.1 & 19.5 \\
\hline
\end{tabular}

Values with different letters in the same column are significantly different $(\mathrm{p} \leq 0.05)$.

a Iodine affinity for pure amylose was assigned as 20\% (Takeda \& Hizukuri, 1987).

b Calculated as: $\mathrm{C}=100 \times \mathrm{IAS} / 0.20$ where $\mathrm{C}$ is the percentage of apparent amylose content and IAS is the iodine affinity of the whole defatted starch.

c Calculated as: $\mathrm{C}=(\mathrm{IAS}-\mathrm{IAAP}) /\{0.20-(\mathrm{IAAP}+\mathrm{IC} / 100)\}$ where $\mathrm{C}$ is the percentage of absolute amylose content, IAS is the iodine affinity of whole defatted starch, and IAAP is the iodine affinity of the amylopectin.

grown (Tester, Debon, Davies, \& Gidley, 1999). Yoo et al. (2009) reported variations between $0.042 \%$ and $0.083 \%$ for different varieties of this starch, while Peroni et al. (2006) found $0.018 \%$ of phosphorous in arrowroot starch.

The potato starch had higher apparent amylose content than arrowroot starch although both of the starches have close absolute amylose contents $(\sim 20 \%)$. This is due to higher proportion of long side chains of amylopectin in potato starch (Yoo et al., 2009). These chains are able to complex with iodine, which contributes to increase the iodine affinity and overestimate the apparent amylose content of starch.

\subsection{Molecular component distribution of starches by GPC}

Molecular component distributions of the gelatinized starches before enzymatic treatment determined by GPC using Sepharose CL 2B gel confirmed that there was no degradation of starches during autoclaving. The amylose fraction of arrowroot starch had lower molecular weight and a narrower molecular weight distribution than that of potato starch (data not shown).

Starch hydrolysis before debranching was performed in such a way that both starches presented similar degrees of hydrolysis ( $25 \%)$, regardless of the enzyme used, so that this parameter would not be another variable.

Molecular component distributions of the starches after enzymatic action are shown in Fig. 1. The average chain lengths of starch fractions at peaks II and III and the percentages of the distribution of the peaks I, II, and III are shown in Table 2. The chromatograms of the debranched potato and arrowroot starches (Fig. 1a and d) exhibited similar profiles with three distinct peaks in addition to a peak that represented glucose, which was used as a marker. The first peak (I) corresponded to amylose molecules and very long amylopectin chains, which were eluted in the void volume of the column (55 mL). The second peak (II), eluted at $\sim 75 \mathrm{~mL}$, corresponded to the long chains of amylopectin with a DPn of 38.9 and 35.1 for potato and arrowroot starches, respectively, and the third peak (III) eluted at $105 \mathrm{~mL}$ corresponded to the short Achains of amylopectin (Franco et al., 2010; Kasemsuwan et al., 1995) with a DPn of 16.5 for both the starches. Amylopectin consists of A, B (B1-B4) and C chains. Fractions with DP $<13$ and DP 13-30 make up the short (A) and intermediate (B1) chains, respectively, while the chains with $\mathrm{DP}>30$ correspond to the long chains (B2-B4) (Hizukuri, 1986). The chromatograms of $\beta$-amylase treated starches (Fig. 1b and e) displayed a decrease in peak I, while peak II became broader and flattened. These results represent an increase in the proportion of amylopectin intermediate and long chains (B1, B2). As $\beta$-amylase hydrolyzes the starch chains releasing maltose by exo-action, amylose is only slightly affected by $\beta$-amylase causing all degraded amylose chains to remain in peak I. Then the reduction in peak I was exclusively due to the very long chains (B3-B4) of amylopectin that were broken down into smaller fragments that were eluted at peak II. The heights of peak I in $\beta$-amylase treated potato and arrowroot starches reduced by 16.3 and $6.0 \%$, respectively, which is in agreement with a diminished effect of $\beta$-amylolysis on very long chains as those from
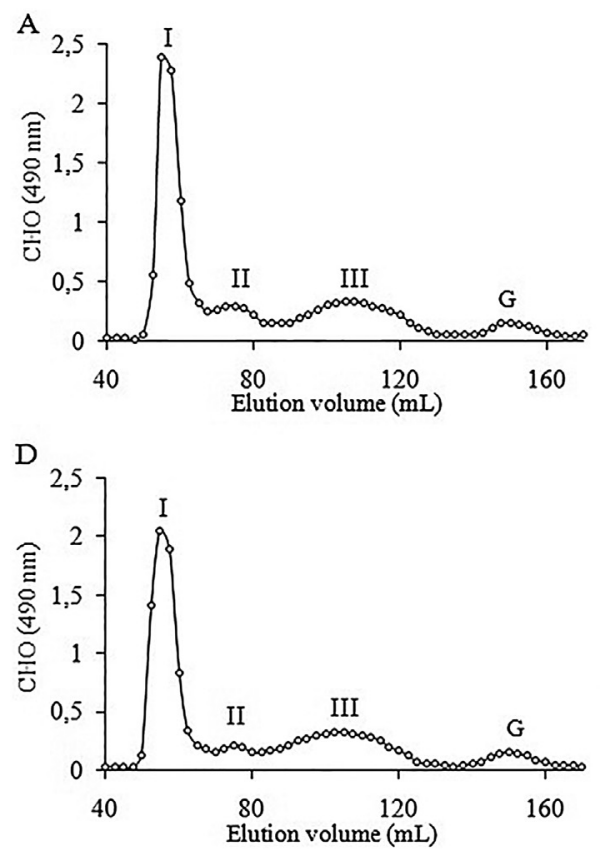

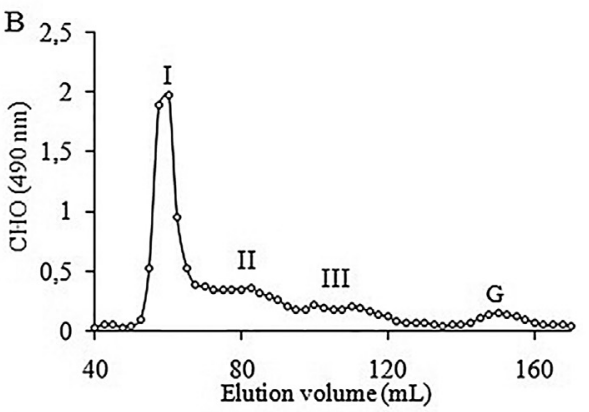

$\mathrm{E}$

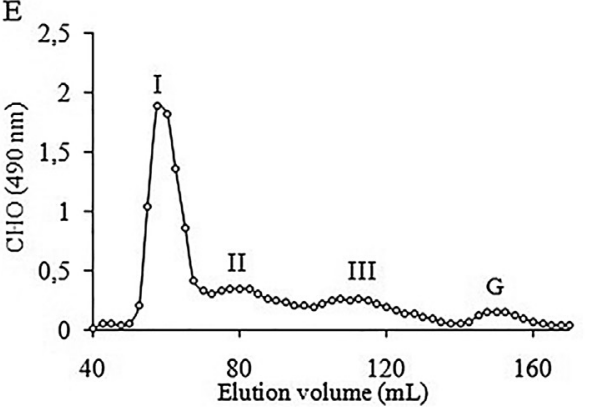

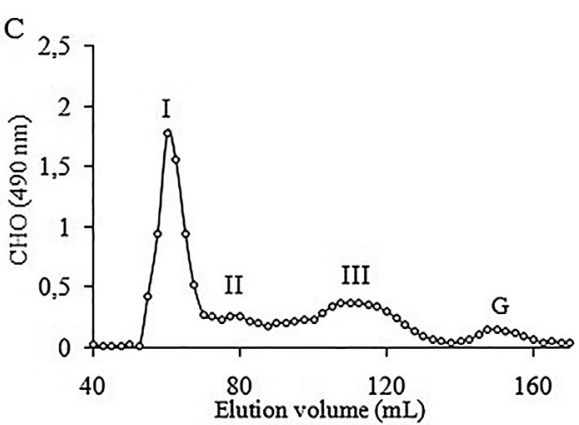

$\mathrm{F}$

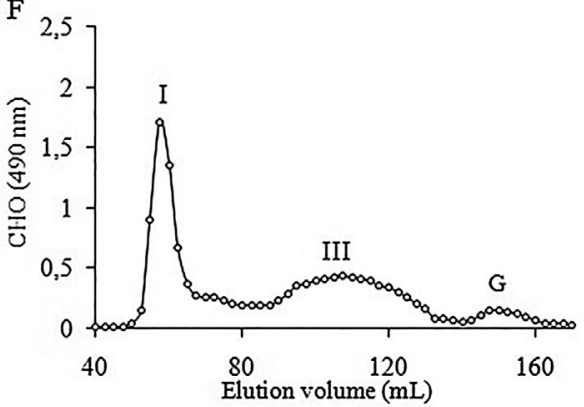

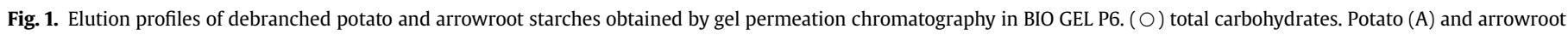
(D) starches; $\beta$-amylase treated potato (B) and arrowroot (E) starches; $\alpha$-amylase treated potato(C) and arrowroot (F) starches; G: glucose. 
Table 2

Summary of amylopectin branch chain length distribution and average molecular weight of the enzyme treated starches and debranched with pullulanase obtained by GPC.

\begin{tabular}{|c|c|c|c|c|c|c|c|}
\hline \multirow[t]{2}{*}{ Starch } & \multicolumn{2}{|c|}{$\begin{array}{l}\text { Average degree of } \\
\text { polymerization }\end{array}$} & \multicolumn{2}{|c|}{$\begin{array}{l}\text { average molecular } \\
\text { weight }\left(10^{3} \mathrm{~g} / \mathrm{mol}\right)\end{array}$} & \multicolumn{3}{|c|}{ Distribution (\%) } \\
\hline & FII & FIII & FII & FIII & FI & FII & FIII \\
\hline PP & $38.9(0.9)$ & $16.5(0.5)$ & 6.3 & 2.7 & 56.1 & 13.0 & 30.9 \\
\hline $\mathrm{P} \beta \mathrm{P}$ & $34.3(0.6)$ & $11.0(0.6)$ & 5.6 & 1.8 & 52.1 & 29.3 & 18.6 \\
\hline $\mathrm{P} \alpha \mathrm{P}$ & $26.8(0.5)$ & $14.0(3.0)$ & 4.4 & 2.3 & 47.5 & 11.7 & 40.8 \\
\hline $\mathrm{AP}$ & $35.1(3.1)$ & $16.7(0.7)$ & 5.7 & 2.7 & 56.3 & 10.0 & 33.7 \\
\hline $\mathrm{A} \beta \mathrm{P}$ & $32.3(3.1)$ & $12.0(1.5)$ & 5.2 & 2.0 & 50.8 & 25.4 & 23.8 \\
\hline $\mathrm{A} \alpha \mathrm{P}$ & $28.2(0.4)$ & $15.3(0.3)$ & 4.6 & 2.5 & 44.0 & 9.5 & 46.5 \\
\hline
\end{tabular}

a Calculated as Mw $=162 \times$ DP +18 . FI: fraction I; FII: fraction II; FIII: fraction III.

b Average of the two replicates followed by standard deviation; PP: debranched potato starch; AP: debranched arrowroot starch; P $\beta \mathrm{P}$ : debranched $\beta$-amylase treated potato starch; $\mathrm{A} \beta \mathrm{P}$ : debranched $\beta$-amylase treated arrowroot starch; $\mathrm{P} \alpha \mathrm{P}$ : debranched $\alpha$-amylase treated potato starch; A $\alpha \mathrm{P}$ : debranched $\alpha$-amylase treated arrowroot starch.

amylose. The peak III also decreased. This result indicates that the short chains with a DPn of 16.5 were hydrolyzed to smaller and more soluble oligosaccharides. The exo-action of $\beta$-amylase implies that in principle every single chain has equal probability to be attacked regardless of its DP and that the same absolute amount of maltose is released from every single chain. As a consequence the DP of shorter chain populations is affected more than that of the longer ones, which is expected to result in a significant decrease in population III for both $\beta$-amylase treated starches. This is clearly observed in Fig. 1 and Table 2.

On the other hand, the fungal $\alpha$-amylase caused the most significant decreases in fraction I and especially in fraction II in that it increased the release of short chains. Fungal $\alpha$-amylase acts by endo-scission releasing large quantities of maltose plus other small oligosaccharides (Reeve, 1992). This means that the number of scission events in a single chain is dependent on its DP and long chains are expected to be affected most. On the other hand, it has been demonstrated that at moderate degrees of hydrolysis $\alpha$ amylase acts on amylopectin preferentially between the clusters rather than within the dense clusters (Gérard, Planchot, Colonna, \& Bertoft, 2000; Goesaert, Bijttebier, \& Delcour, 2010). Indeed, very long chains (peak I) are more affected by $\alpha$-than by $\beta$-amylolysis according to Fig. 1 and Table 2. Peak I might consist mainly of long amylopectin chains within clusters, whilst amylose is more accessible to $\alpha$-amylase. The rather strong reduction in population II suggests that part of these chains were originally long enough to be cleaved at least once. Population III is shown to increase, which suggests that (1) these chains were protected from $\alpha$-amylolysis because being 'within cluster', whereas (2) at the same time this fraction was enriched from populations I and II. No matter which enzyme was used, degradation seemed to be more significant in the arrowroot starch. Bijttebier, Goesaert, and Delcour (2010) observed similar results using size-exclusion chromatography when studying the mechanism of action of different enzymes that were used to treat waxy maize starch.

\subsection{Distribution of the length of the branched chains of amylopectin by HPAEC-PAD}

The normalized amylopectin branch chain length distributions of the starches are displayed in Fig. 2, and the results summarized in Table 3. The potato and arrowroot starches were found to exhibit bimodal distributions with a first peak observed at DP 13 and a second peak at DP 46 (Fig. 2a and d). The potato starch had a higher DPn due to its higher proportion of long chains ( $D P \geq 37$ ) when compared to the arrowroot starch. Similar results were observed by Jane et al. (1999) and Yoo et al. (2009) when they evaluated the amylopectin branch chain length distributions of tuber and root starches using isoamylase as a debranching enzyme.

The amylolysis before debranching caused an overall decrease in the proportion of long and intermediate chains and an increase in the proportion of short chains, although the behavior of the starches acted upon by both $\alpha$ - and $\beta$-amylases has differed.

The $\beta$-amylase treated starches were found to exhibit a significant decrease in the proportion of intermediate chains (DP 13-24) and a less significant decrease in chains with a DP $\geq 37$ (Table 3 ). $\beta$ amylase is an exoenzyme that breaks down the $\alpha$-1,4-linkages and
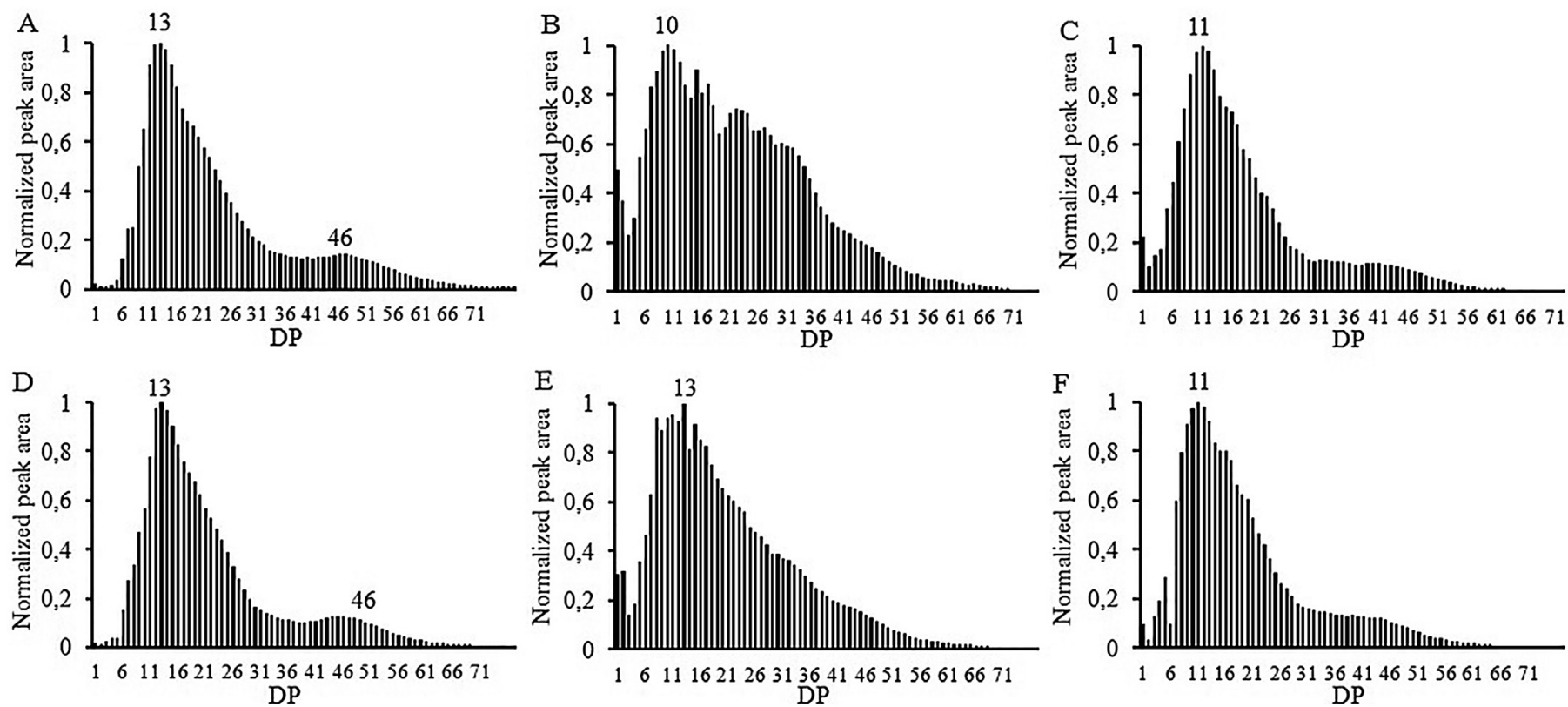


amylase treated potato (C) and arrowroot (F) starches. DP: degree of polymerization. 
Table 3

Amylopectin branch chain length distribution of the enzyme treated starches and debranched with pullulanase determined by HPAEC-PAD. ${ }^{a}$

\begin{tabular}{|c|c|c|c|c|c|c|c|}
\hline & \multicolumn{4}{|c|}{ Branch chain length distribution (\%) } & \multirow[t]{2}{*}{$\mathrm{DP} \geq 37$} & \multirow[t]{2}{*}{$\overline{D P}$} & \multirow[t]{2}{*}{ Highest detected DP } \\
\hline & DP $1-5$ & DP 6-12 & DP13-24 & DP25-36 & & & \\
\hline PP & $0.5(0.1)$ & $20.6(0.2)$ & $47.4(0.4)$ & $15.3(0.1)$ & $16.3(0.4)$ & 23 & 80 \\
\hline $\mathrm{P} \beta \mathrm{P}$ & $6.9(0.3)$ & $22.4(0.1)$ & $32.6(0.3)$ & $24.5(0.2)$ & $13.6(0.3)$ & 21.8 & 77 \\
\hline $\mathrm{P} \alpha \mathrm{P}$ & $5.9(0.2)$ & $34.0(0.3)$ & $40.1(0.5)$ & $10.1(0.1)$ & $9.9(0.2)$ & 17.9 & 77 \\
\hline AP & $0.7(0.1)$ & $21.2(0.3)$ & $50.8(0.3)$ & $14.0(0.1)$ & $13.2(0.3)$ & 21.5 & 80 \\
\hline $\mathrm{A} \beta \mathrm{P}$ & $5.6(0.3)$ & $24.5(0.4)$ & $37.9(0.1)$ & $19.6(0.5)$ & $12.4(0.2)$ & 20.9 & 77 \\
\hline $\mathrm{A} \alpha \mathrm{P}$ & $4.0(0.1)$ & $29.6(0.3)$ & $43.0(0.2)$ & $12.3(0.3)$ & $11.0(0.1)$ & 19.2 & 77 \\
\hline
\end{tabular}

a Average of the two replicates followed by standard deviation; PP: debranched potato starch; AP: debranched arrowroot starch; P $\beta P$ : debranched $\beta$-amylase treated potato

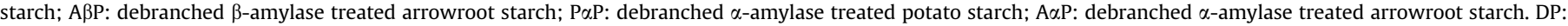
degree of polymerization.

releases maltose plus maltotriose from linear chains with uneven DP (Bijttebier et al., 2010; Robyt, 2009). In this way, it causes a significant increase in the proportion of very short (DP 1-5) chains and chains with a DP 25-36 as also could be observed by increasing of the population II in Fig. 1.

When fungal $\alpha$-amylase was used before debranching, there was decrease in the proportions of chains with DP 13-24, DP 25-36, and $D P \geq 37$, and a significant increase in the proportion of chains with DP 6-12. These results were more pronounced in the potato starch. As fungal $\alpha$-amylase is an endoenzyme, the differences in the impact of the enzymes on the different starches depend on enzyme action mechanism and different structural characteristics of the starches, particularly on the distribution of amylopectin chain length. This effect was also clearly observed in the GPC results (Fig. 1, Table 2).

\subsection{X-ray diffraction and relative crystallinity}

The X-ray diffraction patterns and relative crystallinities of the native and retrograded enzyme treated starches are shown in Fig. 3. The native potato starch displayed a B-type crystalline pattern (Fig. 3A) that is characteristic of tuber starch, with main peaks at $5.6^{\circ}, 17^{\circ}, 22^{\circ}$, and $24^{\circ}$ in $2 \theta$. These results agreed with the findings reported by other authors (Alvani, Qi, Tester, \& Snape, 2011; Yoo et al., 2009).

Meanwhile, the native arrowroot starch was found to have an Atype crystalline pattern (Fig. $3 \mathrm{~B}$ ) characterized by main peaks at $15^{\circ}, 17^{\circ}, 18^{\circ}$, and $23^{\circ}$ (Buleón, Colonna, Planchot, \& Ball, 1998). This type of crystalline pattern was also observed by Moorthy (2002) in a study on arrowroot starch. Retrogradation resulted in the formation of a B-type crystalline pattern (Sievert, Czuchajowska, \& Pomeranz, 1991) in all of the starches studied. Polesi and Sarmento (2011), and Zhou et al. (2014) also found B-type crystalline patterns in their studies on retrograded chickpea and rice starches, respectively. The relative crystallinities of native potato and arrowroot starches were $39.4 \%$ and $37.7 \%$, respectively. According to Zobel (1988), native starches have relative crystallinities varying between $15 \%$ and $45 \%$. The diffractograms of all of the retrograded potato and arrowroot starches displayed more intense and defined peaks compared to those of the corresponding native starches (Fig. 3A, B, b, c and d). This difference means that these retrograded starches are composed of recrystallized amylose chains, debranched amylopectin fragments, and smaller amylose fragments with more appropriate lengths for reassociating and cocrystallizing during retrogradation (Leong, Karim, \& Norziah, 2007). As a result, the starches are more crystalline and possibly more resistant to digestive enzymes. The retrograded debranched potato and arrowroot starches were found to exhibit higher relative crystallinities than their corresponding native starches, because the action of pullulanase released more adequately reassociated chains. When amylolysis preceded debranching, there was a $16.2 \%$ increase in relative crystallinity of the $\beta$-amylase treated arrowroot starch and of $37.4 \%$ when the fungal $\alpha$-amylase was used. However, the increases in relative crystallinities of the enzyme treated potato starches were less significant $13.6 \%$ and $16.5 \%$ in $\beta$-amylase treated potato starch and fungal $\alpha$-amylase treated potato starch, respectively) when compared with debranched starch. Zhou et al. (2014) also observed increases in relative crystallinities in rice starches
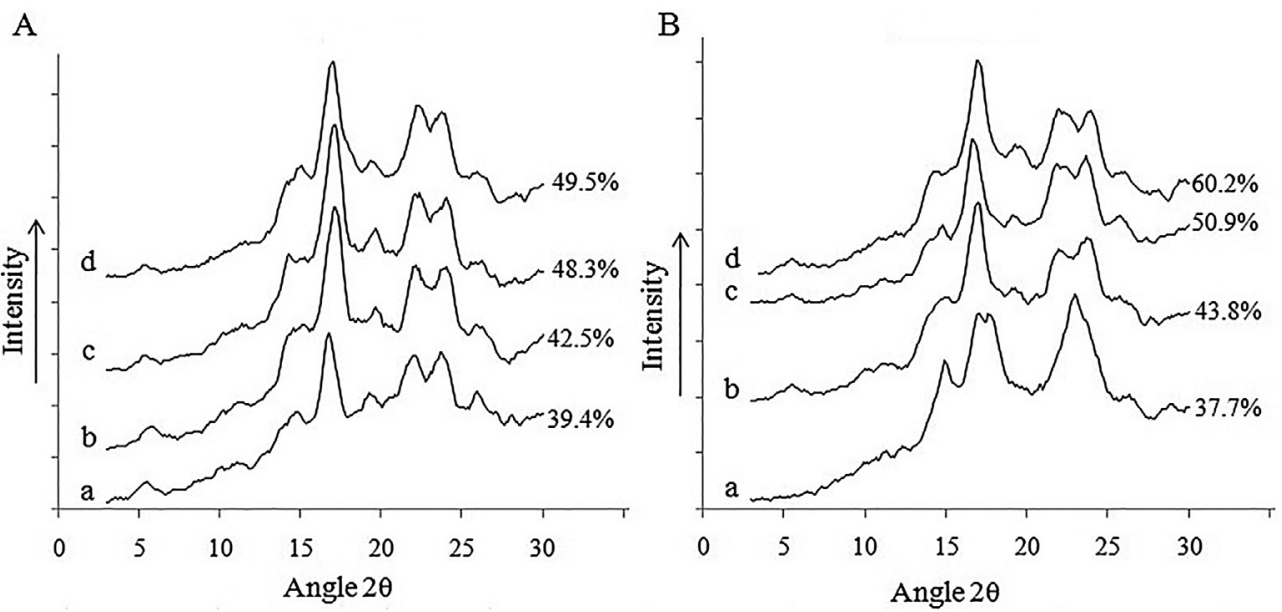

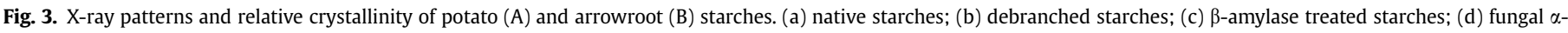
amylase treated starches. 
exposed to enzymatic hydrolysis and then retrograded at $4{ }^{\circ} \mathrm{C}$. The action of both of the enzymes on the potato and arrowroot starches caused a reduction in the size of both the amylose chains and long and intermediate amylopectin chains, which, after debranching, all presented higher mobility that aided in their crystallization.

Amylopectin branch chain length distribution and the molecular size of arrowroot starch amylose aided in the action of the fungal $\alpha$ amylase and resulted in the formation of linear chains with more appropriate sizes that were also prone to reassociation and crystallization.

\subsection{Thermal properties}

The native potato starch had lower gelatinization temperatures than the arrowroot starch (Fig. 4). The high phosphorus content in the potato starch may have contributed to this result (Alvani et al., 2011). This starch was also found to have a higher proportion of long chains (Tables 2 and 3) that formed longer double helices. A larger proportion of long chains requires more energy to melt the crystals (Singh, Singh, Kaur, Sodhi, \& Gill, 2003), a factor which explains the higher $\Delta \mathrm{H}(16.54 \mathrm{~J} / \mathrm{g})$ of the potato starch than of the arrowroot starch $(13.74 \mathrm{~J} / \mathrm{g})$.

All of the retrograded starches displayed a broad endothermic transition (between $49{ }^{\circ} \mathrm{C}$ and $112^{\circ} \mathrm{C}$, Fig. 4). This large amplitude, which was more pronounced in starches that were exposed to amylolysis, indicates higher heterogeneity in the B-type crystals formed after retrogradation, which have different melting temperatures and levels of stability (Moates, Noel, Parker, \& Ring, 1997).

The retrograded debranched starches presented high enthalpies $(10.22 \mathrm{~J} / \mathrm{g}$ and $11.11 \mathrm{~J} / \mathrm{g}$ in potato and arrowroot starches, respectively). These values increased when the amylolysis preceded debranching (13.31 J/g and $14.37 \mathrm{~J} / \mathrm{g}$ in potato starch and $15.45 \mathrm{~J} / \mathrm{g}$ and $19.53 \mathrm{~J} / \mathrm{g}$ in arrowroot starch when $\beta$-amylase and fungal $\alpha$ amylase were used, respectively). These findings are consistent with the relative crystallinity results (Fig. 3). The increases in the enthalpy and relative crystallinity of the enzyme treated starches suggest the strengthening of double helices and the formation of a more organized crystalline structure after the debranching and retrogradation of these starches. These changes likely occurred because of the increase in the proportion of shorter chains and the decrease in the proportion of longer chains of amylopectin, processes which increased the formation of strongly bonded double helices (Luckett \& Wang, 2012; Zhou et al., 2014). The presence of very long chains hinders crystallization and can reduce the density and the stability of the retrograded crystals (Genkina, Wikman, Bertoft, \& Yuryev, 2007).

\subsection{Contents of rapidly digestible starch (RDS), slowly digestible} starch (SDS) and resistant starch (RS)

Because of high thermal stability of RS3 (Fuentes-Zaragosa et al., 2011), the resistant starches obtained were not heated before being analyzed by the method of Englyst et al. (1992).

Gelatinized arrowroot starch exhibited high digestibility, with 93.1\% RDS (Table 4). This level of digestibility is one of the reasons why this starch is recommended for use in food products for convalescents and infant (John, Raja, Rani, Moorthy, \& Eliasson, 2002). However, the potato starch exhibited $8.1 \%$ RS and $18.0 \%$ SDS. The potato starch granules are classified as RS2. Gelatinization degrades resistant starches, but some amount remains preserved in potato starch. The phosphate groups naturally present in this starch are covalently bonded to the glucose residues in the $B$ chains of amylopectin and play a steric hindrance that limits the access of digestive enzymes (Absar et al., 2009; Alvani et al., 2011; Yoo et al., 2009).

The RS3 contents in the retrograded debranched potato and arrowroot starches were similar both were close to $21 \%$ (Table 4 ). However, the retrograded debranched arrowroot starch exhibited 23.3\% SDS. This starch fraction is important for slow and prolonged releasing glucose levels in the blood (Kittisuban et al., 2014). A larger proportion of SDS in retrograded debranched arrowroot starch is related to the structural characteristics of this starch, and particularly to the larger proportion of short chains and the smaller proportion of long chains compared to the potato starch (Tables 2 and 3). According to Guraya, James, and Champagne (2001), SDS formation may be the result of imperfect crystal formation. These imperfect crystals are more apt for digestion than the crystals found in RS.

Amylolysis before debranching caused a significant increase in RS content in both starches. The breakdown of the starch molecules into lower molecular weight fragments increased the number of
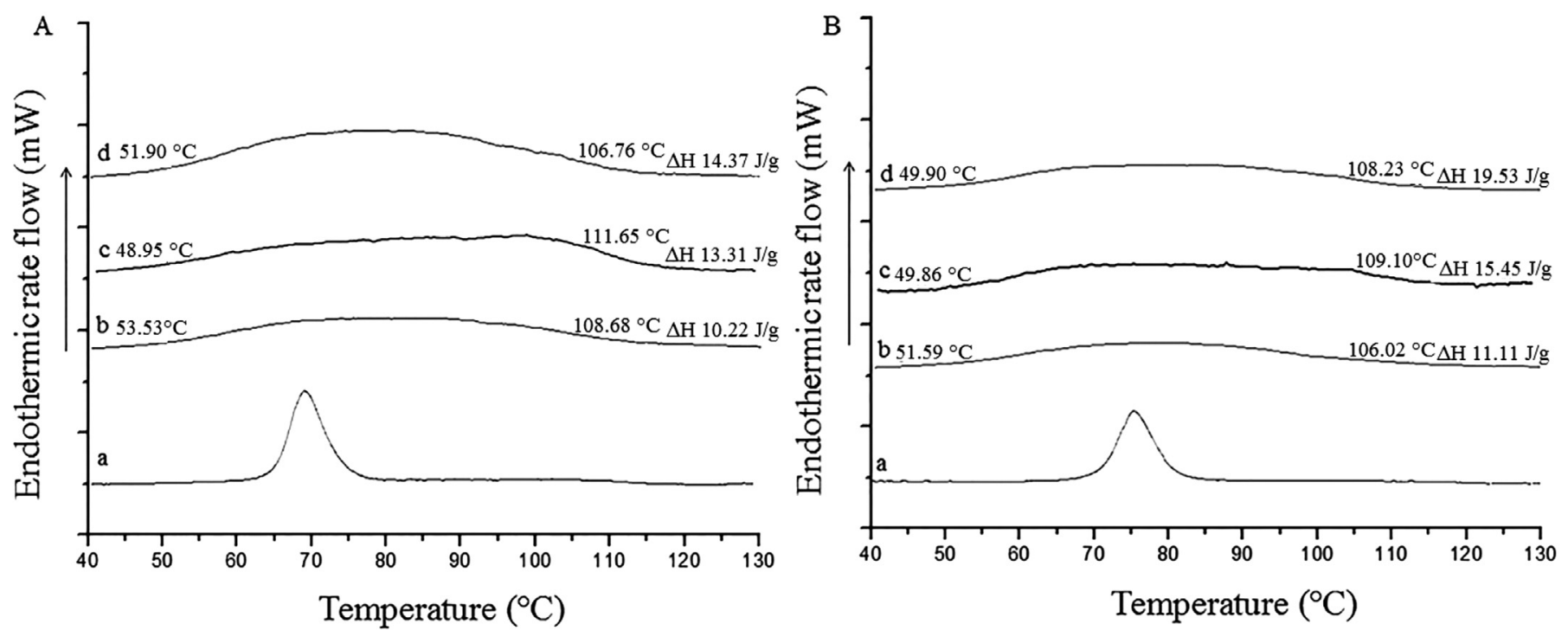

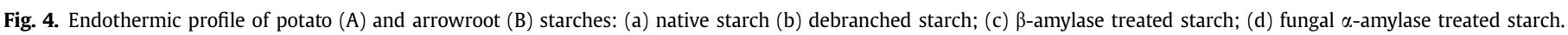
$\Delta \mathrm{H}=$ enthalpy change. 
Table 4

Rapidly digestible starch (RDS), slowly digestible starch (SDS), and resistant starch (RS) contents in the potato and arrowroot starches subjected to different enzymatic treatments and retrograded. ${ }^{\mathrm{a}}$

\begin{tabular}{llrr}
\hline Treatment & RDS(\%) & \multicolumn{1}{c}{ SDS(\%) } & \multicolumn{1}{c}{ RS(\%) } \\
\hline PG & $72.9(0.8)^{\mathrm{b}}$ & $18(0.6)^{\mathrm{c}}$ & $8.1(0.5)^{\mathrm{e}}$ \\
PP & $70.1(0.7)^{\mathrm{c}}$ & $8.5(1.2)^{\mathrm{f}}$ & $20.2(0.6)^{\mathrm{d}}$ \\
P $\beta \mathrm{P}$ & $51.5(0.4)^{\mathrm{e}}$ & $11.3(1.1)^{\mathrm{e}}$ & $36.3(0.7)^{\mathrm{c}}$ \\
P $\alpha \mathrm{P}$ & $34.5(1.1)^{\mathrm{g}}$ & $27.8(0.9)^{\mathrm{a}}$ & $36.8(0.5)^{\mathrm{c}}$ \\
AG & $93.1(0.9)^{\mathrm{a}}$ & $4.7(0.9)^{\mathrm{g}}$ & $1.10(0.5)^{\mathrm{f}}$ \\
AP & $53.9(1.1)^{\mathrm{d}}$ & $23.3(0.6)^{\mathrm{b}}$ & $21.7(0.6)^{\mathrm{d}}$ \\
A $\beta \mathrm{P}$ & $37.8(1.3)^{\mathrm{f}}$ & $13.7(0.7)^{\mathrm{d}}$ & $47.5(0.4)^{\mathrm{b}}$ \\
A $\alpha \mathrm{P}$ & $34.1(1.0)^{\mathrm{g}}$ & $11.3(0.7)^{\mathrm{e}}$ & $53.4(0.5)^{\mathrm{a}}$ \\
\hline
\end{tabular}

${ }^{a}$ Average of three replicates followed by standard deviation. Values followed by different letters in the same column differ significantly by Tukey test ( $\mathrm{p} \leq 0.05)$. PG: gelatinized potato starch; AG: gelatinized arrowroot starch; PP: debranched potato starch; AP: debranched arrowroot starch; P $\beta \mathrm{P}$ : debranched $\beta$-amylase treated potato starch; A $\beta \mathrm{P}$ : debranched $\beta$-amylase treated arrowroot starch; $\mathrm{P} \alpha \mathrm{P}$ : debranched $\alpha$-amylase treated potato starch; A $\alpha \mathrm{P}$ : debranched $\alpha$-amylase treated arrowroot starch.

smaller linear molecules with greater mobility and an increased tendency toward retrogradation (Luckett \& Wang, 2012). Fungal $\alpha$ amylase treated arrowroot starch had the highest percentage of RS, while the potato starch exhibited $36.5 \%$ of RS regardless of the enzyme used. However, the $\alpha$-amylase treatment enhanced SDS formation in potato starch. These results indicate that the amylose content, the molecular mass of starch components, and the amylopectin side chain lengths all strongly influence the formation of RS3. The linear fractions released after fungal $\alpha$-amylase action followed by debranching in the arrowroot starch were more appropriate in size for reassociation. This difference makes their pairing and recrystallization easier and hinders the access of digestive enzymes.

The optimum chain length for RS formation is still a matter of debate because of apparently contradictory findings. In this work, the highest RS content was obtained from linear chains with DPn $\sim 15$, which were in high proportion (Table 2). Eerlingen et al. (1993) observed that RS3 may be formed by aggregating the double helices along a region of chains with approximately 24 glucose units, since chains with DP 14-24 play a positive effect on retrogradation (Silverio, Fredriksson, Andersson, Eliasson, \& Aman, 2000). Gidley and Bulpin (1987) observed that oligosaccharides with DP $>6$ in the presence of longer chains contribute to the formation of double helices.

The increase in the proportion of short chains seems have a positive influence on formation of more resistant B-type crystals to digestive enzymes. High correlation coefficients of RS3 with crystallinity $(r=0.99$ and $r=0.95$, for potato and arrowroot starches, respectively) and also with melting enthalpy $(r=0.93$ and $r=0.89$ for potato and arrowroot starches, respectively) were obtained. Indeed many workers have obtained good quality A- or B-type crystals from short linear chains (DPn 15) prepared by acid degradation (Crochet, Beauxis-Lagrave, Noel, Parker, \& Ring, 2005; LeCorre, Bras, \& Dufresne, 2012), with high melting enthalpy (Whittam, Noel, \& Ring, 1990). On the order hand, according to Eerlingen et al. (1993), maximum RS yields in amylose are obtained from linear chains with DPn $\geq 100$. Gidley \& Bulpin. (1989) observed most rapid crystallization in monodisperse amylose at DP ca 100 , whilst chains with DP $<100$ formed precipitates rather than gels, which is likely to promote RS formation. However, these results were obtained using purified amylose instead of debranched starch. A possible explanation of these apparent discrepancies is that optimum chain length for crystallization may be affected by chain length distribution, which is different for amylose, acid-degraded starch, and debranched starch.

\section{Conclusion}

Amylolysis preceding debranching is effective in reducing starch digestibility. Fungal $\alpha$-amylase is more efficient than bacterial $\beta$ amylase in this process. The structural characteristics of starch and particularly amylopectin side chain length distribution are important factors in RS3 formation when amylolysis precedes debranching. The RS3 formation is enhanced when there is both a decrease in the proportion and DP of long chains and an increase in the proportion of short chains especially with DP $\sim 15$.

\section{Acknowledgments}

The authors thank the Brazilian agencies, CAPES and CNPq, for the financial support.

\section{References}

AACC.. (2000). Approved methods of the American association of cereal chemists. Sant Paul, MN: American Association of Cereal Chemists.

Absar, N., Zaidul, I. S. M., Takigawa, S., Hashimoto, N., Matsuura-Endo, C., Yamauchi, H., et al. (2009). Enzymatic hydrolysis of potato starches containing different amounts of phosphorus. Food Chemistry, 112, 57-62.

Allen, J. D., \& Thoma, J. A. (1978). Repetitive attack by Aspergillus oryzae alpha amylase. Carbohydrate Research, 61, 377-385.

Avaltroni, F., Bouquerand, P. E., \& Normand, V. (2004). Maltodextrin molecular weight distribution influence on the glass transition temperature and viscosity in aqueous solutions. Carbohydrate Polymers, 58, 323-334.

Alvani, K., Qi, X., Tester, R. F., \& Snape, C. E. (2011). Physico-chemical properties of potato starches. Food Chemistry, 125, 958-965.

Berry, C. S. (1986). Resistant starch: formation and measurement of starch that survives exhaustive digestion with amylolytic enzymes during the determination of dietary fibre. Journal of Cereal Science, 4, 2283-2287.

Bijttebier, A., Goesaert, H., \& Delcour, J. A. (2010). Hydrolysis of amylopectin by amylolytic enzymes: structural analysis of the residual amylopectin population. Carbohydrate Research, 345, 235-242.

Buleón, A., Colonna, P., Planchot, V., \& Ball, S. (1998). Starch granules: structure and biosynthesis - mini review. International Journal of Biological Macromolecules, 23, 85-112.

Crochet, P., Beauxis-Lagrave, T., Noel, T. R., Parker, R., \& Ring, S. G. (2005). Starch crystal solubility and starch granule gelatinisation. Carbohydrate Research, 340, 107-113.

Dubois, M., Gilles, K. A., Hamilton, J. K., Rebers, P. A., \& Smith, F. (1956). Colorimetric method for determination of sugar and related substances. Analytical Chemistry, $28,350-353$.

Eerlingen, R. C., Deceuninck, M., \& Delcour, J. A. (1993). Enzyme-resistant starch.II. Influence of amylose chain length on resistant starch formation. Cereal Chemistry, 70, 345-350.

Englyst, H. N., Kingman, S. M., \& Cummings, J. H. (1992). Classification and measurement of nutritionally important starch fractions. European Journal of Clinical Nutrition, 46, 33-50.

Franco, C. M. L., Ogawa, C., Rabachini, T., Rocha, T. S., Cereda, M. P., \& Jane, J. (2010). Effect of lactic acid and UV irradiation on the cassava and corn starches. Brazilian Archives of Biology and Technology, 53, 443-454.

Fuentes-Zaragoza, E., Sánchez-Zapata, E., Sendra, E., Sayas, E., Navarro, C., Fernandez-López, J., et al. (2011). Resistant starch as prebiotic: a review. Starch/Stärke, 63, 406-415.

Genkina, N. K., Wikman, J., Bertoft, E., \& Yuryev, V. P. (2007). Effects of structural imperfection on gelatinization characteristics of amylopectin of starches with A- and B-type crystallinity. Biomacromolecules, 8, 2329-2335.

Gérard, C., Planchot, V., Colonna, P., \& Bertoft, E. (2000). Relationship between branching density and crystalline structure of A- and B-type maize mutant starches. Carbohydrate Research, 326, 130-144.

Gidley, M. J., \& Bulpin, P. V. (1987). Crystallisation of malto-oligosaccharides as models of the crystalline forms of starch: minimum chain-length requirement for the formation of double helices. Carbohydrate Research, 161, 291-300.

Gidley, M. J., \& Bulpin, P. V. (1989). Aggregation of amylose in aqueous systems: the effect of chains length on phase behavior and aggregation kinetics. Macromolecules, 22, 341-346.

Goesaert, H., Bijttebier, A., \& Delcour, J. V. (2010). Hydrolysis of amylopectin by amylolytic enzymes: level of inner chain attack as an important analytical differentiation criterion. Carbohydrate Research, 345, 397-401.

Guraya, H. S., James, G., \& Champagne, E. T. (2001). Effect of enzyme concentration and storage temperature on the formation of slowly digestible starch from cooked debranched rice starch. Starch/Stärke, 53, 131-139.

Hasjim, J., \& Jane, J. (2009). Production of resistant starch by extrusion cooking of acid-modified normal-maize starch. Journal of Food Science, 74, 556-562.

Hizukuri, S. (1986). Polymodal distribution of the chain lengths of amylopectin and its significance. Carbohydrate Research, 147, 342-347. 
Hizukuri, S., Takeda, Y., \& Yasuda, M. (1981). Multi-branched nature of amylose and the action of debranching enzymes. Carbohydrate Research, 94, 205-213.

Jane, J., \& Chen, J. F. (1992). Effect of amylose molecular size and amylopectin branch chain length on paste properties of starch. Cereal Chemistry, 69, 60-65.

Jane, J., Chen, Y. Y., Lee, L. F., Mcpherson, A. E., Wong, K. S., Radosavljevic, M., et al. (1999). Effects of amylopectin branch chain length and amylose content on the gelatinization and pasting properties of starch. Cereal Chemistry, 76, 629-637.

John, J. K., Raja, K. C. M., Rani, S., Moorthy, S. N., \& Eliasson, A. (2002). Properties of arrowroot starch treated with aqueous $\mathrm{HCl}$ at ambient temperature. Journal of Food Science, 67, 10-14.

Kasemsuwan, T., Jane, J., Schnable, P., Stinard, P., \& Robertson, D. (1995). Characterization of the dominant mutant amylose-extender (ae1-5180) maize starch. American Association of Cereal Chemists, 72, 457-464.

Kittisuban, P., Lee, B., Suphantharika, M., \& Hamaker, B. R. (2014). Slow glucose release property of enzyme-synthesized highly branched maltodextrins differs among starch sources. Carbohydrate Polymers, 107, 182-191.

LeCorre, D., Bras, J., \& Dufresne, A. (2012). Influence of native starch's properties on starch nanocrystals thermal properties. Carbohydrate Polymers, 87, 658-666.

Leong, Y. H., Karim, A. A., \& Norziah, M. H. (2007). Effect of pullulanase debranching of sago (Metroxylonsagu) starch at subgelatinization temperature on the yield of resistant starch. Starch/Starke, 59, 21-32.

Lim, S., Kasemsuwan, T., \& Jane, J. (1994). Characterization of phosphorus in starch by ${ }^{31} \mathrm{P}$-nuclear magnetic resonance spectroscopy ${ }^{1}$. Cereal Chemistry, 71, 488-493.

Liu, R., \& Xu, G. (2008). Effects of resistant starch on colonic preneoplastic aberrant crypt foci in rats. Food and Chemical Toxicology, 46, 2672-2679.

Luckett, C. R., \& Wang, Y. (2012). Effects of $\beta$-amylolysis on the resistant starch formation of debranched corn starches. Journal of Agricultural and Food Chemistry, 60, 4751-4757.

Moates, G. K., Noel, T. R., Parker, R., \& Ring, S. G. (1997). The effect of chain length and solvent interactions on the dissolution of the B-type crystalline polymorph of amylose in water. Carbohydrate Research, 298, 327-333.

Moorthy, S. N. (2002). Physicochemical and functional properties of tropical tuber starches: a review. Starch/Starke, 54, 559-592.

Morita, T., Hayashi, J., Motoi, H., Yagishita, T., Takeya, K., \& Sugiyama, K. (2005) In vitro and in vivo digestibility of recrystallized amylose and its application for low glycemic foods. Journal of Food Science, 70, 179-185.

Nara, S., \& Komiya, T. (1983). Studies on the relationship between water-saturated state and crystallinity by the diffraction method for moistened potato starch. Starch/Starke, 35, 407-410.

Peroni, F. H. G., Rocha, T. S., \& Franco, C. M. L. (2006). Some structural and physicochemical characteristics of tuber and root starches. Food Science and Technology International, 12, 505-513.
Polesi, L. F., \& Sarmento, S. B. S. (2011). Structural and physicochemical characterization of RS prepared using hydrolysis and heat treatments of chickpea starch. Starch/Starke, 63, 226-235.

Reddy, C. K., Suriya, M., \& Haripriya, S. (2013). Physico-chemical and functional properties of resistant starch prepared from red kidney beans (Phaseolus vulgaris L) starch by enzymatic method. Carbohydrate Polymers, 95, 220-226.

Reeve, A. (1992). Starch hydrolysis: process and equipment. In F. W. Schenck, \& R. E. Hebeda (Eds.), Starch hydrolysis products (pp. 79-120). New York: VCH Publishers.

Robyt, J. F. (2009). Enzymes and their action on starch. In J. BeMiller, \& R. Whistler (Eds.), Starch: Chemistry and technology (pp. 237-292). Amsterdam: Acabemic Press.

Sievert, D., Czuchajowska, Z., \& Pomeranz, Y. (1991). Enzyme-resistant starch. III. Xray diffraction of autoclaved amylomaize VII starch and enzyme-resistant starch residues. Cereal Chemistry, 68, 86-91.

Silverio, J. Fredriksson, H., Andersson, R., Eliasson, A. C., \& Aman, P. (2000). The effect of temperature cycling on the amylopectin retrogradation of starches with different amylopectin unit-chain length distribution. Carbohydrate Polymers, 42, 175-184.

Singh, N., Singh, J., Kaur, L., Sodhi, N. S., \& Gill, B. S. (2003). Morphological, thermal and rheological properties of starches from different botanical sources. Food Chemistry, 81, 219-231.

Smith, A. R. \& Caruso, T. E. (1964). Determination of phosphorous content. In R. L. Whistler (Ed.), Methods in carbohydrate chemistry, starch, 4 pp. 43-47). New York: Academic Press.

Song, Y., \& Jane, J. (2000). Characterization of barley starches of waxy, normal, and high amylose varieties. Carbohydrate Research, 41, 365-377.

Takeda, Y., \& Hizukuri, S. (1987). Structures of rice amylopectins with low and high affinities for iodine. Carbohydrate Research, 168, 79-88.

Tester, R., Debon, S. J., Davies, H. V., \& Gidley, M. J. (1999). Effect of temperature on the synthesis composition and physical properties of potato starch. Journal of the Science of Food and Agriculture, 79, 2045-2051.

Whittam, M. A., Noel, T. R., \& Ring, S. G. (1990). Melting behaviour of A- and B-type crystalline starch. International Journal of Biological Macromolecules, 12, 359-362.

Yoo, S. H., Perera, C., Shen, J., Ye, L., Suh, D. S., \& Jane, J. L. (2009). Molecular structure of selected tuber and root starches and effect of amylopectin structure on their physical properties. Journal of Agricultural and Food Chemistry, 57, 1556-1564.

Zhou, Y., Meng, S., Chen, D., Zhu, H., \& Yuan, H. (2014). Structure characterization and hypoglycemic effects of dual modified resistant starch from indica rice starch. Carbohydrate Polymers, 103, 81-86.

Zobel, H. F. (1988). Starch crystal transformations and their industrial importance. Starch/Starke, 40, 44-50. 